\title{
Acceptability of oral liquid pharmaceutical products in older adults: palatability and swallowability issues
}

Emilie Belissa ${ }^{1}$, Thibault Vallet ${ }^{2}$, Sandra Laribe-Caget ${ }^{3}$, Alain Chevallier ${ }^{4}$, François-Xavier Chedhomme ${ }^{4}$, Fattima Abdallah ${ }^{5}$, Nathalie Bachalat ${ }^{5}$, Sid-Ahmed Belbachir ${ }^{6}$, Imad Boulaich ${ }^{5}$, Vanessa Bloch ${ }^{7}$, Anne Delahaye ${ }^{8}$, Mathieu Depoisson ${ }^{9}$, Amélie Dufaÿ Wojcicki ${ }^{1}$, Stéphane Gibaud ${ }^{10}$, Anne-Sophie Grancher ${ }^{3}$, Caroline Guinot ${ }^{7}$, Celia Lachuer ${ }^{5}$, Laurent Lechowski ${ }^{8}$, Patrick Leglise ${ }^{5}$, Abdel Mahiou $^{6}$, Sylvie Meaume ${ }^{3}$, Corinne Michel ${ }^{6}$, Hugues Michelon ${ }^{8}$, Yann Orven ${ }^{9}$, Ines Perquy ${ }^{4}$, Matthieu Piccoli ${ }^{4}$, Maïté Rabus ${ }^{5}$, Annie-Claude Ribemont ${ }^{5}$, Jean-Paul Rwabihama ${ }^{5}$, Jean-Hugues Trouvin ${ }^{1}$, Fabrice Ruiz ${ }^{2}$ and Vincent Boudy ${ }^{1 *}$

\begin{abstract}
Background: In institutional care, oral liquid pharmaceutical products are widely prescribed for older patients, especially for those with swallowing disorders. As medicines acceptability is a key factor for compliance in the older population, this study investigated the acceptability of oral liquid pharmaceutical products in this targeted population.

Methods: An observational, multicenter, prospective study was conducted in eight geriatric hospitals and eight nursing homes in France. Observers reported several behaviours/events describing the many aspects of acceptability for various pharmaceutical products' uses in patients aged 65 and older. Acceptability scores of oral liquid pharmaceutical products were obtained using an acceptability reference framework (CAST - ClinSearch Acceptability Score Test ${ }^{\circledast}$ ): a 3D-map summarizing the different users' behaviors, with two clusters defining the positively and negatively accepted profiles materialized by the green and red zones, respectively.
\end{abstract}

Results: Among 1288 patients included in the core study and supporting the acceptability reference framework, 340 assessments were related to the administration of an oral liquid pharmaceutical product. The mean age of these patients was 87 (Range [66-104y]; SD =6.7), 68\% were women and 16\% had swallowing disorders. Globally, the oral liquid pharmaceutical products were classified as "positively accepted," the barycenter of the 340 assessments, along with the entire confidence ellipses surrounding it, were positioned on the green zone of the map. Sub-populations presenting a different acceptability profile have also been identified. For patients with swallowing disorders, the oral liquid pharmaceutical products were classified as "negatively accepted," the barycenter of the 53 assessments along with $87 \%$ of its confidence ellipses were associated with this profile. A gender difference was observed for unflavored oral liquids. In women, they were classified "negatively accepted," the barycenter of the 68 assessments with 75\% of its confidence ellipses were located in the red zone, while they were classified "positively accepted" in men.

(Continued on next page)

\footnotetext{
* Correspondence: vincent.boudy@aphp.fr

'Département Recherche et Développement Pharmaceutique, Agence

Générale des Equipements et Produits de Santé (AGEPS), Assistance

Publique-Hôpitaux de Paris (AP-HP), 7 rue du Fer à Moulin, 75005 Paris,

France

Full list of author information is available at the end of the article
}

(c) The Author(s). 2019 Open Access This article is distributed under the terms of the Creative Commons Attribution 4.0 International License (http://creativecommons.org/licenses/by/4.0/), which permits unrestricted use, distribution, and

reproduction in any medium, provided you give appropriate credit to the original author(s) and the source, provide a link to the Creative Commons license, and indicate if changes were made. The Creative Commons Public Domain Dedication waiver (http://creativecommons.org/publicdomain/zero/1.0/) applies to the data made available in this article, unless otherwise stated. 
(Continued from previous page)

Conclusion: This study showed that oral liquid pharmaceutical products are a suboptimal alternative to solid oral dosage forms in patients with swallowing disorders. To ensure an optimal acceptability, prescribers should also consider the presence of a taste-masker in these oral liquids. As highlighted herein, palatability remains crucial in older populations, especially for women.

Keywords: Medicine acceptability, Older population, Palatability, Swallowability, Oral liquids

\section{Background}

Nearly $10 \%$ of older patients are hospitalized owing to non-compliance to their daily intake of prescribed medications [1]. Medicine acceptability is likely to have a significant impact on patient adherence in these older populations and consequently on the efficiency and safety of treatments as well as overall quality of life. Patient acceptability in the older population has been recently defined by the European Medicines Agency (EMA) as "the ability and willingness of the patient to self-administer and also any of their lay or professional caregivers, to administer the medicinal product as intended" [2]. It is a multidimensional concept, depending on characteristics of the drug product - such as route of administration, appearance, swallowability, and characteristics of the patients themselves - such as age and pathological state, in both pediatric and older populations [2, 3]. To ensure medicine acceptability for each of these populations, appropriate pharmaceutical products must be developed [4, 5].

Altered swallowing function is a common disability concerning 2 to $16 \%$ of the community-dwelling older population, affecting up to $60 \%$ of patients in some institutions $[6,7]$. This age-related swallowing impairment is a major issue compromising the use of the most prescribed formulation in older patients, the solid oral dosage form (SODF). Consequently, SODF are frequently subject to alterations, mainly crushing, at the time of administration [8]. Although dysphagia may be diagnosed using the drink test, measuring the time needed to swallow $80 \mathrm{~mL}$ of water [7], recourse to oral liquid pharmaceutical products is a widely used alternative to SODF in an attempt to ease medicine administration for these patients with swallowing disorders [9]. Despite the many well-known drawbacks for the older population (e.g., risk of dosage errors or an incomplete administration, risk of excipient overload [2]), switching from SODF to oral liquid formulations nonetheless remains a common practice in institutional care.

Oral liquid pharmaceutical products encompass readyto-use oral liquids (i.e., oral solutions or suspensions) as well as the reconstituted oral liquids (i.e., powders or effervescent tablets which must be dissolved or dispersed in a liquid prior to administration). Many active pharmaceutical ingredients (API) have a bitter taste [10], for which excipients are frequently used as masking agents. Although palatability is known to be an important acceptability driver in pediatrics [3], it is usually not considered to be a major issue for older patients in hospitals and nursing homes, due to the increasing prevalence of dysgeusia with age, and polymedication in this population [11-16].

This study investigated the impact of both users and products characteristics on acceptability of oral liquid pharmaceutical products in such an older population.

\section{Methods \\ Objective, study design and setting}

The objective of this multicenter, prospective, crosssectional, and strictly observational study, was to identify those pharmaceutical products less accepted in the older population. The study was conducted between October 2016 and August 2018 in 8 French hospitals and 8 nursing homes.

\section{Participants}

Inclusion criteria required that patients were 65 -years-old and older, hospitalized or residing in a nursing home, receiving any medicine. Patients receiving intravenous medication where the intravenous device is already in situ were excluded, as the insertion of such a device was considered as part of the acceptability. All patients answering these criteria, and who have assented verbally to participating in the study, were included without any randomization. The observer reports were recorded anonymously. Being a non-interventional study, patients were maintained under their current treatment, no modifications or additions to their prescriptions were made during the observational period.

\section{Data collection}

CAST - ClinSearch Acceptability Score Test ${ }^{\oplus}$, is a tool integrating many aspects of acceptability to discriminate between positively and negatively accepted medicines in vulnerable populations. CAST was initially developed for the pediatric population $[17,18]$, and has since been transposed for the older population [19].

This tool includes observer reports corresponding to several observations of behaviors/events performed during the medicine use: patient's reaction during the administration 
(positive, neutral or negative reaction), result of the administration (the dose is fully, partly or not taken at all), time needed to prepare (from opening any packaging to having a required dose ready to use, including all handling and modifications), and time to administer the required dose of medication (from a required dose of medication ready to use to the end of the intake). The preparation and administration time was classified as $20 \mathrm{~s}$ or shorter, medium time, or longer than one minute. In addition, observers were required to report recourse to any methods used to ease/ achieve administration. This might include dividing the intake of a dose which cannot be taken as a whole; altering the intended use (modify the dosage form such as tablet crushed or capsule opened; use another route/mode of administration; use a device not provided); use of food/ drink to mask a taste or ease swallowing; use of restraint (the patient had to force himself or was opposed taking the medication). These observational variables were collected prospectively by observers in order to score acceptability.

Each evaluation of one medication taken by one patient corresponding to a particular combination of observed measures was related to information on the product, the patient and the context of use [19], as described briefly hereafter. Demographic parameters (e.g. sex) and comorbidities (e.g. swallowing disorders) were recorded from the patient's medical record, while information on the pharmaceutical products (e.g. pharmaceutical form, presence of flavoring agent) were extracted from the summary of product characteristics (SmPC). These explanatory variables were collected in order to investigate their impact on acceptability.

\section{Statistical analyses}

To describe the many aspects of acceptability, previously described observations were included in a multivariate analysis without weighting. Using mapping and clustering processes, an intelligible acceptability reference framework was designed: a three-dimensional acceptability map was created that juxtaposed two clusters of evaluations, each defining a contrasting acceptability profile. All of the evaluations were positioned on the map depending on their similarity: the most similar evaluations converged. Positively connoted observations were over-represented in the first cluster of evaluations defining the "Positively accepted" profile (green area on the map), while negatively connoted evaluations were over-represented in the second cluster defining the "Negatively accepted" profile (red area on the map).

The reference framework was used to investigate the impact of characteristics of both users (gender and presence of swallowing alteration) and drug products

Table 1 Demographic Characteristics of the Patients

\begin{tabular}{|c|c|c|c|}
\hline Characteristics of patients $(n=340)$ & & $\mathrm{n}$ & $(\%)$ \\
\hline \multirow[t]{3}{*}{ Sex } & Women & 230 & (68) \\
\hline & Men & 107 & (32) \\
\hline & $m d^{a}: 3$ & & \\
\hline \multirow[t]{5}{*}{ Age (years) } & {$[65,75]$} & 13 & (4) \\
\hline & {$[75,85]$} & 111 & (33) \\
\hline & {$[85,95]$} & 172 & (50) \\
\hline & {$[95,104]$} & 43 & (13) \\
\hline & md: 1 & & \\
\hline \multirow[t]{2}{*}{ Place } & Hospital & 304 & (89) \\
\hline & Nursing home & 36 & (11) \\
\hline \multirow[t]{6}{*}{ Disabilities } & Swallowing disorder & 53 & (16) \\
\hline & md: 4 & & \\
\hline & Muscular or rheumatologic disorders of the upper limbs & 81 & (24) \\
\hline & md: 6 & & \\
\hline & Cognitive impairment & 210 & $(62)$ \\
\hline & md: 4 & & \\
\hline \multirow[t]{4}{*}{ Number of prescribed medicines per day } & $1-4$ & 31 & (9) \\
\hline & $5-9$ & 147 & (43) \\
\hline & $\geq 10$ & 161 & (48) \\
\hline & md: 1 & & \\
\hline
\end{tabular}


(presence of flavoring agents) on acceptability of the oral liquid pharmaceutical products.

To obtain an acceptability score the barycenter of the evaluations of interest (e.g. those related to the flavored formulations) was positioned on the map. A barycenter, along with the entire $90 \%$ confidence ellipses surrounding it, belonging to the "positively accepted" profile, could be considered as accepted. Due to differences among patients, we consider a minimum of 30 evaluations to get a robust acceptability score. In cases with fewer than this threshold, we cannot draw any conclusion and only note any tendency that might be observed.

Pearson's Chi-squared test was used to assess the significance of the differences observed between the subpopulations of patients related to the different acceptability scores, in terms of gender and swallowing disorders [20].
The $\mathrm{R}$ packages "FactoMineR" [21] and "MissMDA" [22] were used to perform multivariate analysis and to handle missing data, respectively ( $\mathrm{R}$ version 3.4.4).

\section{Results}

\section{Patients and medicines}

Among the 1288 evaluations included in the multivariate analysis that gave rise to the final acceptability reference framework, there were 340 evaluations of oral liquid pharmaceutical products. The mean age of these patients was 87 (6.7), the minimum age was 66, the maximum was 104 , and $68 \%$ were women. Thirty five percent of patients had taken ready-to-use oral liquids and the remaining $65 \%$ had taken reconstituted oral liquids. Table 1 presents the demographic characteristics of these patients and the features of the 59 distinct pharmaceutical products are summarized in Table 2 .

Table 2 Characteristics of the Medicines

\begin{tabular}{|c|c|c|c|}
\hline \multicolumn{2}{|c|}{ Characteristics of medicines $(n=59)$} & \multirow{2}{*}{$\begin{array}{l}\mathrm{n} \\
17\end{array}$} & \multirow{2}{*}{$\frac{(\%)}{(29)}$} \\
\hline Formulations & Oral solution & & \\
\hline & Powder for oral solution & 11 & (19) \\
\hline & Oral suspension & 6 & (10) \\
\hline & Powder for oral suspension & 4 & (7) \\
\hline & Drops for oral solution & 4 & (7) \\
\hline & Divisible effervescent tablet & 3 & (5) \\
\hline & Dispersible tablet & 3 & (5) \\
\hline & Other $(2 \%<n<5 \%)$ : Syrup; Effervescent tablet. & & \\
\hline & $\begin{array}{l}\text { Other }(n \leq 2 \%) \text { : Powder for oral and rectal solution; } \\
\text { Oral gel; Injection and oral solution; Prolonged release } \\
\text { granules; Divisible tablet for oral suspension; Dispersible } \\
\text { or chewable tablet; Dispersible coated tablet }\end{array}$ & & \\
\hline \multirow[t]{3}{*}{ Flavoring agents } & Presence & 40 & (70) \\
\hline & Absence & 17 & (30) \\
\hline & $m d^{a}: 2$ & & \\
\hline \multirow{9}{*}{$\begin{array}{l}\text { Therapeutic subgroups } \\
\text { (ATC }{ }^{\mathrm{b}}-2 \text { nd level) }\end{array}$} & Analgesics & 10 & (17) \\
\hline & Drugs for constipation & 8 & (14) \\
\hline & Psycholeptics & 7 & (12) \\
\hline & Antiepileptics & 7 & (12) \\
\hline & Psychoanaleptics & 4 & (7) \\
\hline & Mineral supplements & 4 & (7) \\
\hline & Antibacterials for systemic use & 4 & (7) \\
\hline & $\begin{array}{l}\text { Other }(2 \%<n<5 \%) \text { : Drugs used in diabetes; Drugs for acid } \\
\text { related disorders; Antithrombotic agents }\end{array}$ & & \\
\hline & $\begin{array}{l}\text { Other ( } \mathrm{n} \leq 2 \%) \text { : Thyroid therapy; Beta blocking agents; } \\
\text { Anti-parkinson drugs; All other non-therapeutic products; } \\
\text { Antimycotics for systemic use; Antimycobacterials; } \\
\text { Antihemorrhagics; Antianemic preparations }\end{array}$ & & \\
\hline
\end{tabular}

\footnotetext{
${ }^{\mathrm{a}}$ md missing data
}

${ }^{b}$ ATC: The Anatomical Therapeutic Chemical (ATC) Classification System is a drug classification system controlled by the World Health Organization Collaborating Centre for Drug Statistics Methodology (WHOCC) 


\section{Acceptability of oral liquid pharmaceutical products}

The barycenter of the 340 evaluations of oral liquid pharmaceutical products, along with the entire 90\% confidence ellipses surrounding it, fell within the "positively accepted" profile cluster. Thus, the oral liquid pharmaceutical products, considered as a whole, were classified as accepted in the older population.

\section{Effect of swallowing alteration in patients}

Among all the patients who had taken oral liquid pharmaceutical products, $16 \%$ had a swallowing disorder. (Figure 1) presents the acceptability scores of oral liquid pharmaceutical products in patients with or without swallowing disorders. This figure highlights the negative impact of dysphagia on the acceptability of such liquid formulations, which could be classified as accepted in patients without a swallowing disorder but not in patients with swallowing disorders.

There were no significant differences between these groups of patients in term of sex $(p=0.999)$ flavored formulation $(p=0.877)$.

\section{Effect of flavoring agents and gender of patients}

A third of the patients $(n=102)$ had taken oral liquids pharmaceutical products that had no flavoring agents added. (Figure 2) presents the acceptability scores of the products formulated with or without flavoring agents. Figure 2 highlights the positive impact of flavoring on the acceptability of these formulations. Those formulated with a flavoring agent could be classified as accepted, while those formulated without any flavoring agent could not, due to a significant part of their confidence ellipses falling within the second cluster.

There were no significant differences between these groups of patients in term of sex $(p=0.814)$ or swallowing disorders $(p=0.877)$.

Figures 3 and 4 investigate palatability issues depending on patients' gender. The oral liquids formulated with flavor seemed to be accepted regardless of patients' gender, as the barycentre, along with the entire confidence ellipses, with the exception of a very limited part of the ellipse in the third dimension for women, belonged to the "positively accepted" profile (Fig. 3). While those formulated without flavor could be classified as accepted in men but not in women (Fig. 4).

There were no significant differences between men and women in terms of swallowing disorders for the oral liquids formulated with flavor $(p=0.732)$ and without flavor $(p=0.661)$.

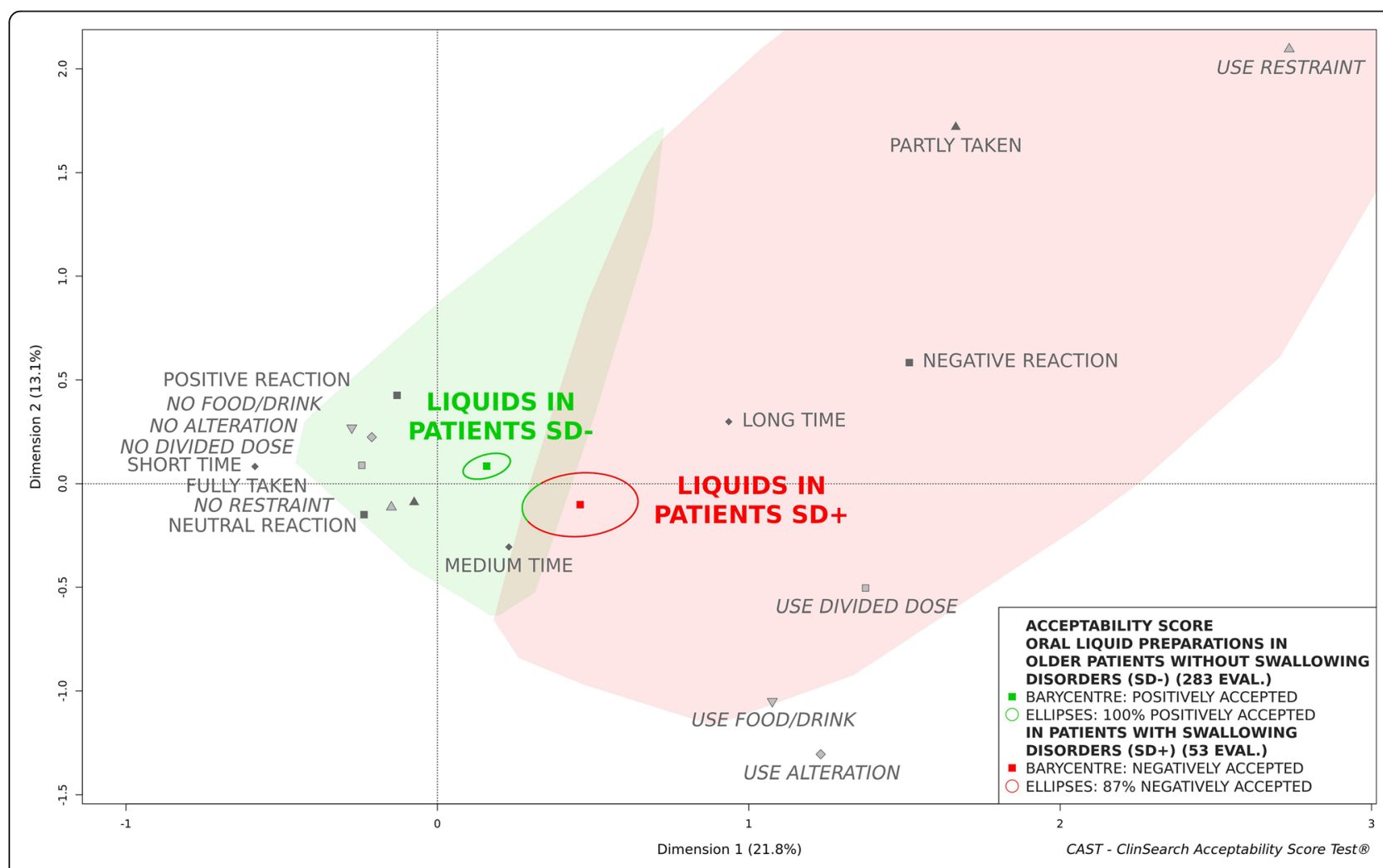

Fig. 1 Acceptability profiles of oral liquid pharmaceutical products in the older patients with (SD+) and without (SD-) swallowing disorders 


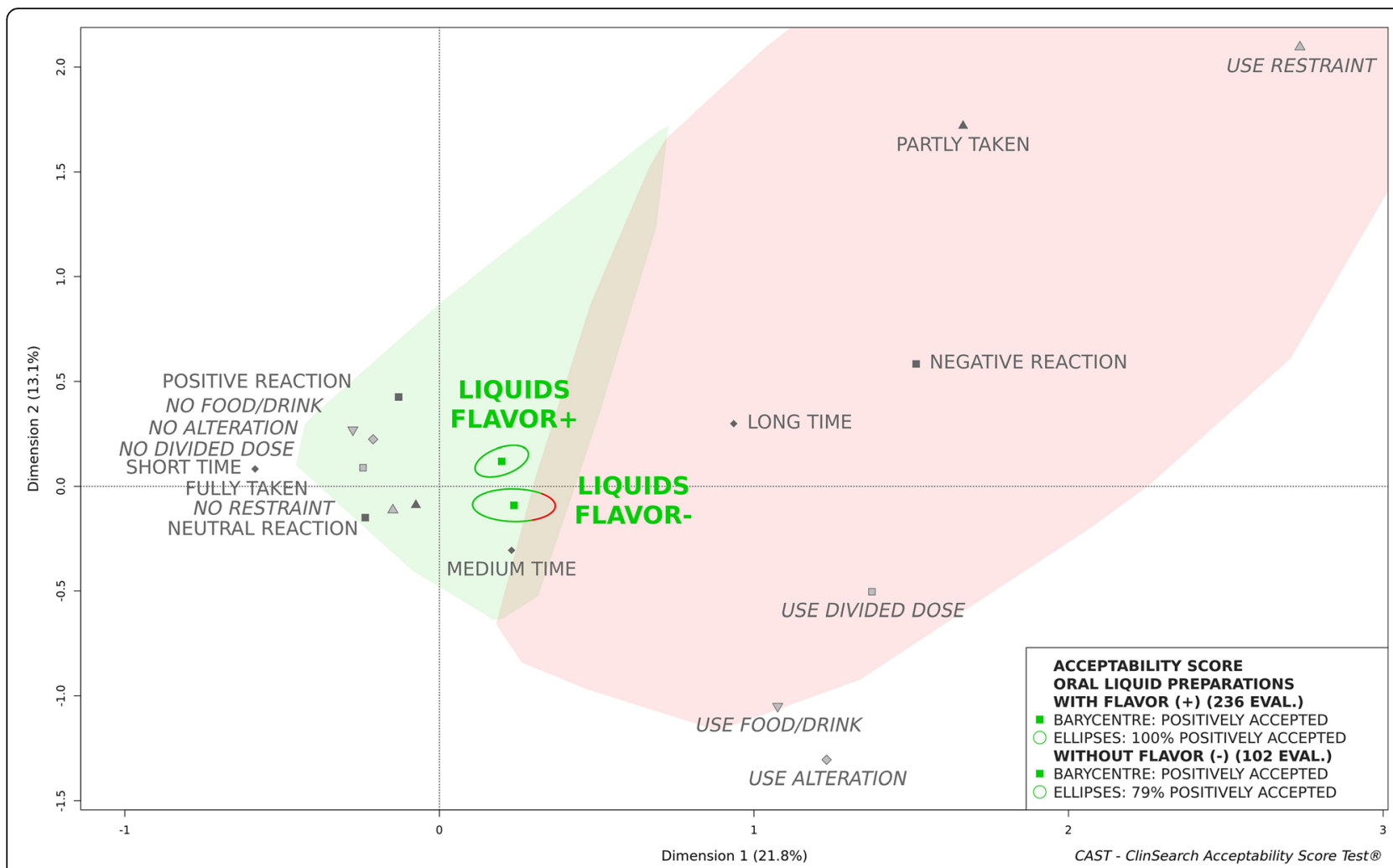

Fig. 2 Acceptability profiles of oral liquid pharmaceutical products with (FLAVOR+) and without (FLAVOR-) flavoring agents

\section{Discussion}

The population studied, receiving pharmaceutical products under the specific dosage form of oral liquids, is representative of the older population classically encountered in hospitals or nursing homes. Most patients were women over 80 years old, a consequence of the longer life expectancy of women $[1,23]$. In this study's population, polymedication of greater than 5 medication per day was observed among $91 \%$ of the patients, which is higher than that previously reported for older populations, e.g., $50 \%$ in the studies of Legrain [1] and Solemdal [13]. However, this could in part be due to the fact that in this study the prescription of "in case of" medications, which is very frequent in the hospital settings, have also been counted for each patient. To avoid or limit any inclusion or selection bias, all patients meeting the inclusion criteria were proposed to participate. Twenty six percent of the patients included in the core study had taken oral liquid pharmaceutical products. Although these products, considered as a whole, were classified as accepted in the older population using the reference framework, this study has revealed acceptability differences driven by both users and products characteristics.

Oral liquid pharmaceutical products were classified as accepted in older patients without any swallowing disorders, while this appeared not to be the case for those with swallowing alterations. These results confirm that recourse to these formulations in the older population with swallowing alterations remains a suboptimal alternative to SODF. As age-related swallowing impairments are nonetheless a common disability affecting oral medicines administration, further investigations are carried out to provide healthcare professionals with relevant knowledge on which formulations (e.g. orodispersible forms) and medicine features (e.g. maximum size of a tablet) ensure an optimal acceptability in these patients.

Oral liquids formulated without any addition of a flavoring agent appeared to be less well accepted than those that were flavored. Highlighting the positive impact of flavoring agents on the acceptability of oral liquid formulations, these results demonstrate the critical aspect of pharmaceutical products' palatability in the older population. In pediatrics, the importance of palatability is well-known [3], have shown that flavors may have a favorable effect on medicines acceptability [24-28]. In the older population, palatability has often been overlooked and commonly overshadowed by swallowability issues. Indeed, initial drafts of the EMA reflection paper on the pharmaceutical development of medicines for use in the older population did not mention palatability as a product characteristic influencing medicines acceptability in the older population [2]. 


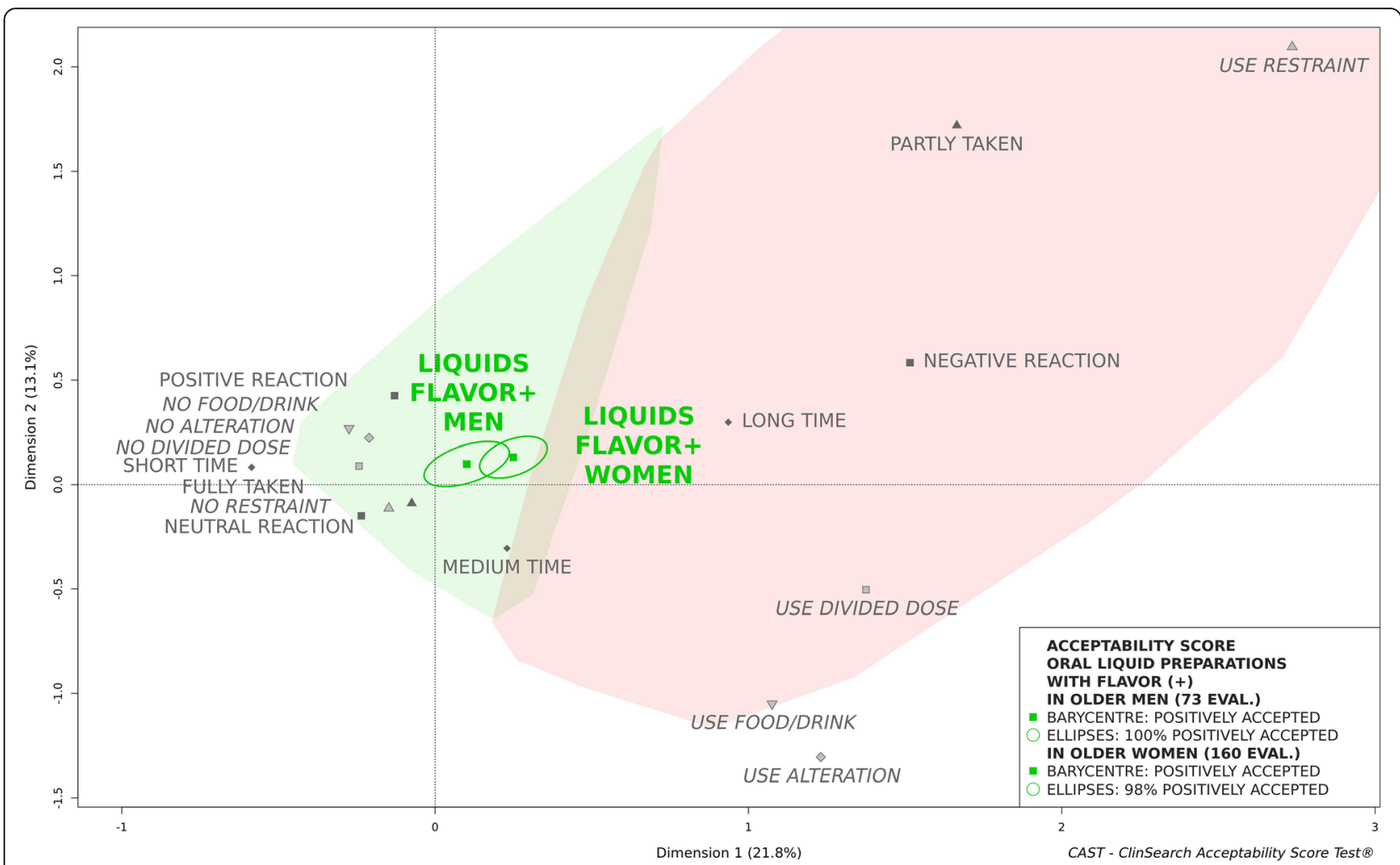

Fig. 3 Acceptability profiles of oral liquid pharmaceutical products with flavor (FLAVOR+) in men and women

Exploring gender acceptability differences, a higher sensitivity among women to the unpalatable oral liquids has been observed. Indeed, contrary to those formulated with flavor which were accepted regardless of patients' gender, oral liquids formulated without any additional flavoring agent were classified as accepted in older men, but not in women. This may be supported by the fact that women usually maintain a higher taste perception than their male counterparts over the course of ageing [11-13, 16]. Therefore, palatability was found to be a key factor of influence upon acceptability, especially for older women.

Further explorations of factors impacting palatability are conducted because other characteristics of patients such as health status (e.g. dementia [29]) could affect smell and taste perception and consequently, medicine acceptability.

Among the 59 distinct pharmaceutical products assessed in this study, 30\% were formulated without any flavoring agents. Overcoming API taste issues through the judicious choice of excipients seems appropriate to ensure liquid preparations acceptability in the older population. However, the potential benefits of excipients should be tempered with regards to safety concerns (e.g. sugars may negatively impact oral health and increase blood glucose levels) as well as particular conditions and any other prescriptions associated with ageing (e.g. multiple long-term therapies resulting in polyols overload may have a laxative effect). Furthermore, the use of certain sweeteners and flavoring agents could be challenging due to issues of stability and/or compatibility with the API in question or other excipients. A better understanding of patients' needs and challenges in elderly formulation development is thus required for the prescription, and development, of dosage forms that are appropriate for each individual.

\section{Conclusion}

This study has demonstrated in an objective manner that both swallowability and palatability issues remain crucial for the acceptability of oral liquid pharmaceutical products in older people hospitalized or receiving institutional care. Indeed, these products are a suboptimal alternative to solid oral dosage forms in patients with swallowing disorders, while their palatability remains an essential acceptability driver in older adults, especially in women. These findings underline the need to promote patient-centered care based on a better understanding of the older patient's needs. 


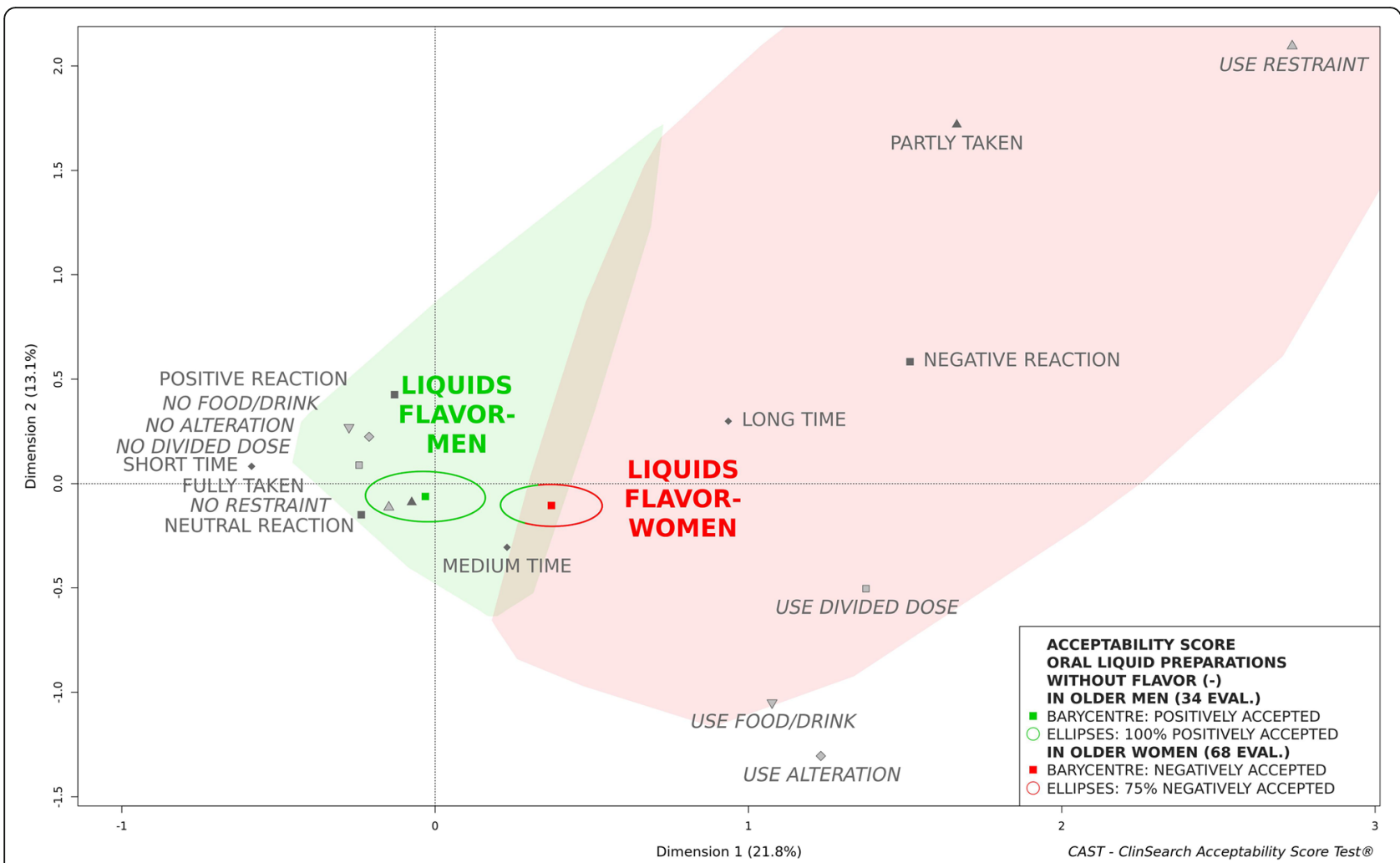

Fig. 4 Acceptability profiles of oral liquid pharmaceutical products without flavor (FLAVOR-) in men and women

\section{Abbreviations}

API: Active pharmaceutical ingredients; CAST: CAST - ClinSearch Acceptability Score Test ${ }^{\oplus}$; EMA: European medicines agency; SmPC: Summary of product characteristics; SODF: Solid oral dosage form

\section{Acknowledgements}

The authors would like to thank all patients for their participation in the study and all members of the working group R2G ("Rencontres Galénique et Gériatrie"). In addition, we gratefully acknowledge all of the healthcare professionals working at the eight hospitals and the eight nursing homes (Résidence Degommier - 91590 Cerny; Résidence Vauban Fondation Claude Pompidou - 90000 Belfort; Maison de retraite protestante - 92000 Nanterre; Maison du parc - 75013 Paris; Résidence John Lennon - 95370 Montigny-lèsCormeilles; Korian Les Arcades - 75012 Paris; Korian Nymphéas Bleus - 27200 Vernon; Korian Samarobriva - 80000 Amiens). Many thanks to all of the students who have actively contributed to the recruitment of patients: Sacha Barsan, Jonathan Mimoun, Laetitia Valery, Ingrid Vallée (Hôpital Rothschild), Hugues Feltize-Nanguem, Isaure Magnus (Hôpital Sainte Périne), Inès Dufier (Hôpital René Muret), Florence du Chayla and Marie Descamps (ClinSearch). Finally, we would like to thank Christopher Jarvis medical writer at ClinSearch for linguistic revision.

\section{Authors' contributions}

VBo and FR are the guarantors. FR and TV develop the acceptability evaluation tool: CAST - ClinSearch Acceptability Score Test ${ }^{\oplus}$. EB, TV, SLC, AC, FXC, PL, MP, HM, VBI, JHT, ADW, FR, and VBo designed the study. EB, SLC, AC, $F X C, P L, M P, H M, V B I, F A, N B, S A B, I B, A D, M D, S G, A S G, C G, C L, L L, A M, S M$, $C M, Y O, I P, M R, A C R$, JPR contributed to data acquisition. TV performed the data analysis. EB and TV draft the paper. EB, TV, ADW, FR, and VBo are major contributors in writing the manuscript. All authors reviewed the manuscript and approved the final version.

\section{Funding}

No funding was received for this study. ClinSearch provided support in the form of salaries for authors TV and FR and provided funding for the Open Acess publication fee, but did not have any additional role in the study design, data collection and analysis, decision to publish, or preparation of the manuscript. The specific roles of these authors are described in the 'author contributions' section. The remaining authors are paid employees of the Assistance Public-Hôpitaux de Paris (AP-HP).

\section{Availability of data and materials}

Data underlying the study cannot be made publicly available due to legal and ethical considerations. European Union (GDPR) and French (Law n ${ }^{\circ} 78-17$ of 6 January 1978) laws restrict the public sharing of personally identifiable data. Requests for data will be processed according to the French MR-003 Code of conduct by the data controller, ClinSearch, which allows for the use of data for the purpose of reproducing study results. Requests to access the data for this purpose may be sent to the data protection officer of ClinSearch: dataprivacy@clinsearch.net, and researchers outside the European Union will need to sign a transfer agreement.

\section{Ethics approval and consent to participate}

The data in this study were exempt from review by an institutional review board as confirmed by on committee ("Comité de Protection des Personnes, Ile-de-France VII). According to the French law (94-548 du 1er juillet 1994, Art. 40-2), the Advisory Committee for Data Processing in Health Research (CCTIRS - "Comité Consultatif sur le Traitement de l'Information en matière de Recherche dans le domaine de la Santé" - 16.390bis) delivered a positive opinion on research methodology, and the French Data Protection Authority (CNIL - "Commission Nationale de l'Informatique et des Libertés" - DR-2017139) approved the data processing. In accordance with the French law (94548 du 1er juillet 1994, Art. 40-4), the patients have been informed (and/or legal representatives) and included in this observational study if they did not express their verbal opposition. 


\section{Consent for publication}

Not applicable.

\section{Competing interests}

The authors declare that they have no financial and personal conflicts of interest.

\section{Author details}

'Département Recherche et Développement Pharmaceutique, Agence Générale des Equipements et Produits de Santé (AGEPS), Assistance Publique-Hôpitaux de Paris (AP-HP), 7 rue du Fer à Moulin, 75005 Paris, France. ${ }^{2}$ ClinSearch, 110 avenue Pierre Brossolette, 92240 Malakoff, France. ${ }^{3}$ Hôpital Rothschild, Groupe Hospitalier Universitaire Est Parisien, AP-HP, 5 rue Santerre, 75012 Paris, France. ${ }^{4}$ Hôpital Broca, Groupe Hospitalier Universitaire Paris Centre, AP-HP, 54-56 rue Pascal, 75013 Paris, France. ${ }^{5}$ Hôpital Joffre Dupuytren, Groupe Hospitalier Universitaire Henri Mondor, AP-HP, 1 rue Eugène Delacroix, 91210 Draveil, France. ${ }^{6}$ Hôpital René Muret, Groupe Hospitalier Universitaire Paris Seine-Saint-Denis, AP-HP, avenue du Dr Schaeffner, 93270 Sevran, France. ${ }^{7}$ Hôpital Fernand Widal, Groupe Hospitalier Universitaire Saint-Louis - Lariboisière - Fernand-Widal, AP-HP, 200 rue du Faubourg Saint-Denis, 75010 Paris, France. ${ }^{8}$ Hôpital Sainte Périne, Groupe Hospitalier Universitaire Paris lle-de-France Ouest, AP-HP, 11 rue Chardon Lagache, 75016 Paris, France. ${ }^{9}$ Hôpital Vaugirard, Groupe Hospitalier Universitaire Paris Ouest, AP-HP, 10 rue Vaugelas, 75015 Paris, France.

${ }^{10}$ Centre Hospitalier de l'Ouest Vosgien, 1280 avenue division Leclerc, 88300 Neufchâteau, France.

Received: 3 April 2019 Accepted: 31 October 2019

Published online: 07 December 2019

\section{References}

1. Legrain S: Consommation médicamenteuse chez le sujet âgé Consommation, prescription, iatrogénie et observance 2005.

2. European Medicine Agency: Draft - Reflection paper on the pharmaceutical development of medicines for use in the older population. In.; 2017

3. European Medicine Agency: Guideline on pharmaceutical development of medicines for paediatric use. In.; 2013.

4. Liu F, Ranmal S, Batchelor HK, Orlu-Gul M, Ernest TB, Thomas IW, Flanagan T, Tuleu C. Patient-centred pharmaceutical design to improve acceptability of medicines: similarities and differences in paediatric and geriatric populations. Drugs. 2014;74(16):1871-89.

5. Stegemann S. Challenges and opportunities in the design of ageappropriate drug products. Z Gerontol Geriatr. 2012;45(6):479-84.

6. Clavé P, Arreola V, Romea M, Medina L, Palomera E, Serra-Prat M. Accuracy of the volume-viscosity swallow test for clinical screening of oropharyngeal dysphagia and aspiration. Clin Nutr. 2008:27(6):806-15.

7. Wirth R, Dziewas R, Beck AM, Clave P, Hamdy S, Heppner HJ, Langmore S, Leischker AH, Martino R, Pluschinski P. Oropharyngeal dysphagia in older persons-from pathophysiology to adequate intervention: a review and summary of an international expert meeting. Clin Interv Aging. 2016;11:189.

8. Stegemann S, Gosch M, Breitkreutz J. Swallowing dysfunction and dysphagia is an unrecognized challenge for oral drug therapy. Int J Pharm. 2012;430(1):197-206

9. Walsh J, Ranmal SR, Ernest TB, Liu F. Patient acceptability, safety and access: a balancing act for selecting age-appropriate oral dosage forms for paediatric and geriatric populations. Int J Pharm. 2017;11(17):-30616.

10. Mennella JA, Spector AC, Reed DR, Coldwell SE. The bad taste of medicines: overview of basic research on bitter taste. Clin Ther. 2013;35(8):1225-46.

11. Imoscopi A, Inelmen EM, Sergi G, Miotto F, Manzato E. Taste loss in the elderly: epidemiology, causes and consequences. Aging Clin Exp Res. 2012; 24(6):570-9

12. Mojet J, Christ-Hazelhof E, Heidema J. Taste perception with age: generic or specific losses in threshold sensitivity to the five basic tastes? Chem Senses. 2001;26(7):845-60

13. Solemdal K, Sandvik L, Willumsen T, Mowe M. Taste ability in hospitalised older people compared with healthy, age-matched controls. Gerodontology. 2014;31(1):42-8.

14. Syed Q, Hendler KT, Koncilja K. The impact of aging and medical status on dysgeusia. Am J Med. 2016;129(7):753 e751-753. e756.
15. Toffanello E, Inelmen E, Imoscopi A, Perissinotto E, Coin A, Miotto F, Donini $L$, Cucinotta D, Barbagallo M, Manzato E. Taste loss in hospitalized multimorbid elderly subjects. Clin Interv Aging. 2013;8:167.

16. Wardwell L, Chapman-Novakofski K, Brewer MS. Effects of age, gender and chronic obstructive pulmonary disease on taste acuity. Int J Food Sci Nutr. 2009;60(sup6):84-97.

17. Ruiz F, Vallet T, Pense-Lheritier AM, Aoussat A. Standardized method to assess medicines' acceptability: focus on paediatric population. J Pharm Pharmacol. 2017:69(4):406-16.

18. Vallet T, Ruiz F, Lavarde M, Pense-Lheritier AM, Aoussat A. Standardized evaluation of medicine acceptability in paediatric population: reliability of a model. J Pharm Pharmacol. 2018;70(1):42-50.

19. Vallet T, Belissa E, Laribe-Caget S, Chevallier A, Chedhomme FX, Leglise $P$, Piccoli M, Michelon $\mathrm{H}$, Bloch $\mathrm{V}$, Meaume $\mathrm{S}$, et al. A decision support tool facilitating medicine Design for Optimal Acceptability in the older population. Pharm Res. 2018;35(7):136

20. Cochran W. Some methods for strengthening the common $\times 2$ tests. Biometrics. 1954:10(4):417-51.

21. Le $\mathrm{S}$, Josse J, Husson F. FactoMineR: an R package for multivariate analysis. J Stat Softw. 2008:25(1):1-18.

22. Josse J, Husson F. missMDA: a package for handling missing values in multivariate data analysis. J Stat Softw. 2016:70(1):1-31.

23. Neouze A, Dechartres A, Legrain S, Raynaud-Simon A, Gaubert-Dahan M-L, Bonnet-Zamponi D. Mode d'hospitalisation des patients âgés dans une unité de gériatrie aiguë. Gériatrie et Psychologie Neuropsychiatrie du Vieillissement. 2012;10(2):143-50.

24. Jahnsen T, Thorn P. An acceptability study of two pivampicillin mixtures in children in general practice. Scand J Prim Health Care. 1987:5(4):241-3.

25. Stevens R, Votan B, Lane R, Schaison G, Hewitt M, Kohler J, Thyss A. A randomized study of ondansetron syrup in children: evaluation of taste acceptability and tolerance. Pediatr Hematol Oncol. 1996;13(2):199-202.

26. Guenther Skokan E, Junkins EP Jr, Corneli HM, Schunk JE. Taste test: children rate flavoring agents used with activated charcoal. Arch Pediatr Adolesc Med. 2001;155(6):683-6.

27. Tolia V, Han C, North JD, Amer F. Taste comparisons for lansoprazole strawberry-flavoured delayed-release orally disintegrating tablet and ranitidine peppermint-flavoured syrup in children. Clin Drug Investig. 2005; 25(5):285-92.

28. Venables $\mathrm{R}$, Batchelor $\mathrm{H}$, Hodson J, Stirling H, Marriott J. Determination of formulation factors that affect oral medicines acceptability in a domiciliary paediatric population. Int J Pharm. 2015;480(1-2):55-62.

29. Churnin I, Qazi J, Fermin CR, Wilson JH, Payne SC, Mattos JL. Association between olfactory and gustatory dysfunction and cognition in older adults. Am J Rhinol Allergy. 2019:33(2):170-7.

\section{Publisher's Note}

Springer Nature remains neutral with regard to jurisdictional claims in published maps and institutional affiliations.

Ready to submit your research? Choose BMC and benefit from:

- fast, convenient online submission

- thorough peer review by experienced researchers in your field

- rapid publication on acceptance

- support for research data, including large and complex data types

- gold Open Access which fosters wider collaboration and increased citations

- maximum visibility for your research: over $100 \mathrm{M}$ website views per year

At BMC, research is always in progress.

Learn more biomedcentral.com/submissions 